\title{
Ocorrências de zircão hafnífero no sudeste brasileiro
}

\author{
Ronaldo Mello Pereira ${ }^{1}$, Ciro Alexandre Ávila ${ }^{2}$ \& Reiner Neumann ${ }^{3}$
}

\begin{abstract}
Resumo Este trabalho descreve as ocorrências brasileiras de zircão rico em háfnio conhecidas até a presente data, provenientes de pegmatitos das províncias pegmatíticas de São João del Rei e Oriental Brasileira (distrito de Governador Valadares), Estado de Minas Gerais e de granitos alcalinos, pertencentes à Suíte Intrusiva Serra do Mar, representados pelo columbita granito Guaraú e riebeckita álcali-granito Mandira, Estado de São Paulo. Os métodos analíticos utilizados para as análises foram a microssonda eletrônica e o MEV-EDS. Os teores (\% em peso) de $\mathrm{HfO}_{2}$ determinados $\geq 10 \%$ e as razões atômicas $(100$. $\mathrm{Hf} / \mathrm{Hf}+\mathrm{Zr})>10 \%$ mol. \% $\mathrm{HfSiO}_{4}$, permitem considerar, formalmente, os diversos grãos estudados como zircão hafnífero. Ele ocorre, geralmente, em cristais milimétricos, euédricos, com formas prismáticas bi-terminadas. Cristais com hábitos flabeliforme e bipiramidal estão relacionados, respectivamente, aos pegmatitos Mixiriqueira e Golconda e ao riebeckita álcali-granito Mandira. As suas cores são rosa, avermelhada, castanha e branca leitosa. As partes mais enriquecidas em háfnio estão, geralmente, próximas às bordas dos cristais. Os teores mais elevados $(\sim 36 \%$, em peso, de $\mathrm{HfO}_{2}$ ) foram observados nos zircões dos pegmatitos. $\mathrm{O}$ zircão hafnífero dos granitos tem teores máximos de $16 \%$ de $\mathrm{HfO}_{2}$ (em peso). A torita é a principal exsolução encontrada no zircão hafnífero derivado dos pegmatitos e dos granitos. Hospedadas nas amostras de zircão hafnífero provenientes dos pegmatitos, ocorrem inclusões minerais de: cassiterita, microlita, niobotantalatos, xenotímio e chernovita. Nos cristais de zircões dos granitos, registram-se inclusões de magnetita, uraninita, monazita, xenotímio e bastnäsita.
\end{abstract}

Palavras-chave: zircão hafnífero, pegmatitos, granitos alcalinos, região sudeste, Brasil.

\begin{abstract}
Hafniferous zircon of the brazilian southeastern region This paper discribes the occurrences of hafniferous zircon related to the pegmatitic and alkaline granite bodies of the southeastern region of Brazil. Hafniferous zircon was found in the pegmatites provinces of the São João del Rei and Oriental Brasileira (Governador Valadares pegmatitic distrite), Minas Gerais State and in granitic bodies of the Serra do Mar Intrusive Suite, São Paulo State. Electron microprobe and SEM/EDS analyses of several grains of hafniferous zircon show high $\mathrm{HfO}_{2}$ content $(\geq 10 \mathrm{wt} \%)$ and atomic ratios $(100 . \mathrm{Hf} / \mathrm{Hf}+\mathrm{Zr})>10 \%$ (mol.) $\mathrm{HfSiO}_{4}$. The hafniferous zircon occurs in milimetric euhedric crystals with prismatic and bipyramidal forms. Flabeliform habit is related to the Mixiriqueira and Golconda pegmatites and bipyramidal crystals to the riebeckite alkalic Mandira granite. Grain sizes vary from less than $1 \mathrm{~mm}$ up to $3 \mathrm{~mm}$, with colours ranging from pink, reddish, brown and milky white. The SEM/BSD images differentiate between ligther Hf-enriched portions (crystal's rim) and darker regions with lower contents of such element. The hafniferous zircon of the pegmatites show higher values (36 wt. $\%$ ) of $\mathrm{HfO}_{2}$ compared to the granites (16 wt.\% of $\left.\mathrm{HfO}_{2}\right)$. Thorite and uraninite are the principal exsolutions of the hafniferous zircon. Cassiterite, microlite, niobotantalates, xenotime and chernovite are the inclusions hosted in the crystals from the pegmatites. Magnetite, uraninite, monazite, xenotime and bastnäsite are the principal inclusions of the granitic zircons.
\end{abstract}

Keywords: hafniferous zircon, pegmatite, alkalic granite, southeastern region, Brazil.

INTRODUÇÃO O háfnio é um elemento que tem aplicação nas indústrias química, cerâmica e nuclear. Um de seus compostos, o carbeto de háfnio, é a substância binária, até agora conhecida, mais refratária ao calor, apresentando ponto de fusão por volta de $3.900^{\circ}$ C. Esse elemento é utilizado na fabricação de vidros e cerâmicas especiais, em eletrodos e, em virtude de sua capacidade de captura de nêutrons térmicos, em barras de controle de reatores nucleares. Ele é um elemento químico raro na natureza. Comumente, o $\mathrm{Hf}^{4+}$ substitui o zircônio $\left(\mathrm{Zr}^{4+}\right)$ na estrutura de minerais, principal- mente no zircão $\left(\mathrm{ZrSiO}_{4}\right)$ e na badelleyíta $\left(\mathrm{ZrO}_{2}\right)$.

$\mathrm{O}$ teor normal de $\mathrm{HfO}_{2}$ no zircão fica em torno de $1 \%$. Porém, em alguns cristais de zircão de pegmatitos da Noruega e da África valores de até 31\% (em peso) de $\mathrm{HfO}_{2}$ (Levinson \& Borup 1960, Knorring \& Hornung 1961) têm sido descritos. Correia-Neves et al. (1974) fizeram a primeira descrição do mineral hafnão ( $72 \%$, em peso, de $\mathrm{HfO}_{2}$ ) em pegmatitos de Moçambique. Na década de 90 surgiram os primeiros registros de granitos portadores de zircão com háfnio. Eles correspondem ao granito de Beauvoir na França (zircão com

1 - Departamento de Geologia Aplicada, Faculdade de Geologia, Universidade do Estado do Rio de Janeiro. Rio de Janeiro, RJ, Brasil. E-mails: rmello@pq.cnpq.br; rmellouerj@hotmail.com

2 - Dep. Geologia e Paleontologia, Museu Nacional, Univ. Federal do Rio de Janeiro. Rio de Janeiro, RJ, Brasil, E-mail ávila@mn.ufrj.br 3 - Centro de Tecnologia Mineral. Rio de Janeiro, RJ, Brasil, E-mail rneumann@cetem.gov.br 
até $18 \%$, em peso, de $\mathrm{HfO}_{2}$ ); ao granito Suzshou (zircão com até $35 \%$, em peso, de $\mathrm{HfO}_{2}$ ); e ao granito Laoshan do tipo-A (zircão com até $12 \%$, em peso, de $\mathrm{HfO}_{2}$ ), estes situados na China (Wang et al. 1996, 2000).

$\mathrm{O}$ zircão enriquecido em háfnio encontra-se, particularmente, relacionado a pegmatitos graníticos e rochas graníticas especializadas em metais raros, sendo que o conteúdo de Hf na estrutura cristalina do zircão tende a aumentar conforme os estágios tardios de cristalização dos mesmos, preferencialmente quando associados às fases mais litiníferas e tantalíferas (Knorring \& Hornung 1961, Correia Neves et al. 1974, Černý \& Silvola 1980, Wang et al. 1996, 2000). Potencialmente, esses corpos correspondem aos principais metalotectos favoráveis à presença de zircão com um alto conteúdo de Hf.

Com o objetivo de inserir o país no quadro mundial de ocorrências de zircão hafnífero, esse trabalho vem apresentar os registros desse mineral, conhecidos, até a presente data, em território brasileiro.

\section{ZIRCÃO HAFNÍFERO NO SUDESTE BRASILEI- RO: HISTÓRICO Até meados da década de 80 não se tinha registro da presença de háfnio no Brasil. A primeira ocorrência foi determinada por Cassedanne et al. (1985) que descreveram zircão hafnífero ( $23 \%$ $\mathrm{HfO}_{2}$ ) associado ao pegmatito Mixiriqueira, região de Ipatinga, MG. Pereira et al. (2003a) apresentaram os resultados obtidos no estudo da segunda ocor- rência brasileira de zircão hafnífero $\left(\sim 30 \% \mathrm{HfO}_{2}\right)$ e do primeiro registro brasileiro de hafnão zirconífero encontrado na região de São João del Rei, Estado de Minas Gerais. Recentemente, foram divulgadas duas novas ocorrências de zircão hafnífero $\left(\mathrm{HfO}_{2} \sim 16 \%\right.$, em peso) associados a granitos alcalinos (às vezes, peral- calinos) da suíte intrusiva Serra do Mar, na região do Vale do Ribeira, São Paulo. Esses corpos são represen- tados pelo plúton Desemborque e pelo riebeckita álca- li-feldspato granito Mandira, encontrados, respectiva- mente, em Jacupiranga/Cajati e Cananéia (Pereira et al. 2003b, 2005). A localização das ocorrências é mostrada na figura 1 .}

MÉTODOS ANALÍTICOS Os resultados das microanálises pontuais efetuadas nas amostras de zircão hafnífero oriundas de pegmatitos e dos granitos (Tabs. 1 e 2) foram obtidas por meio de microssonda eletrônica (Universidade de Brasília) e MEV-EDS (CETEM/ MCT). Maiores detalhes sobre os métodos utilizados para as análises podem ser encontrados em Pereira et al. (2003a, 2004b, 2005). As imagens MEV-BSD foram, por sua vez, efetuadas no Centro de Tecnologia Mineral (CETEM/MCT).

ZIRCÃOHAFNÍFEROASSOCIADOAPEGMATITOS As províncias pegmatíticas de São João del Rei e Oriental Brasileira abrangem extensas áreas localizadas na região sudeste, mais especificamente, no Estado de Minas Gerais. Nela encontram-se dois conjuntos importantes de corpos pegmatíticos. O primeiro in- clui os pegmatitos distribuídos entre Nazareno e São João del Rei e constitui a Província Pegmatítica de São João del Rei. O segundo, representado pela Província Pegmatítica Oriental Brasileira, corresponde a diversos grupamentos de pegmatitos que constituem, dentre outros, os distritos de Araçuaí, Governador Valadares e Caparaó.

\section{Província Pegmatítica de São João del Rei}

CONTEXTO GEOLÓGICO REGIONAL Esta região com aproximadamente $70 \mathrm{~km}$ de comprimento e cerca de $20 \mathrm{~km}$ de largura, está situada no sul do Estado de Minas Gerais. Ela abrange áreas dos municípios de São João del Rei, Nazareno, Cassiterita, Ritápolis e Coronel Xavier Chaves. Na região ocorrem numerosos pegmatitos, geralmente na forma de diques, com mergulhos subverticais, que cortam praticamente todos os litotipos da faixa greenstone Rio das Mortes. Dentre os diversos tipos de rochas ígneas plutônicas intrusivas na faixa greenstone destaca-se o granitóide Ritápolis com idade de $2.121 \pm 7 \mathrm{Ma}$, provável responsável pela geração dos pegmatitos (Ávila 2000). Os corpos pegmatíticos têm extensões normalmente inferiores a $100 \mathrm{~m}$ porém, na área do Volta Grande, Município de Nazareno, registram-se corpos gigantes com até $1000 \mathrm{~m}$ de comprimento e espessuras variáveis que podem chegar a até uma centena de metros. Todos os corpos da província são, particularmente, produtores de cassiterita, tantalita e microlita.

CARACTERIZAÇÃO DO ZIRCÃO Os grãos de zircão hafnífero estudados correspondem a minerais detríticos coletados em córregos cuja carga de leito ativo é atualmente formada pelos rejeitos provenientes das atividades de mineração efetuadas nos numerosos corpos pegmatíticos estanho-tantalíferos aí encontrados. Os locais de coleta situam-se a, no máximo, $100 \mathrm{~m}$ a jusante das lavras pegmatíticas. O material analisado provém dos pegmatitos do Volta Grande (corpo E), do Garimpo do Cascalho Preto e do Córrego Pernambuco situados nos municípios de Nazareno, Coronel Xavier Chaves e São João del Rei, respectivamente. O zircão ocorre em cristais euédricos (Fig. 2) com forma prismática bipiramidal, alguns são geminados, tamanho variando entre 1,0 e $2,0 \mathrm{~mm}$, cor rósea a ligeiramente avermelhada e cor de fluorescência amarelada ao UV ondas curtas. Os teores (em peso) de $\mathrm{ZrO}_{2}, \mathrm{HfO}_{2}, \mathrm{SiO}_{2}$ e $\mathrm{ThO}_{2}$ estabelecidos por microssonda eletrônica e MEV/EDS são apresentados nas tabelas 1 e 2. Nas imagens MEV/BSD (Fig. 3), verifica-se que os cristais são constituídos nas bordas por zonas mais claras, mais enriquecidas em $\mathrm{HfO}_{2}(26,9 \%$ a $36,5 \%$ em peso), e, nas partes mais internas, por zonas escuras, menos enriquecidas em $\mathrm{HfO}_{2}$ $(17,2 \%$ a $21,0 \%$, em peso). O hafnão zirconífero corresponde a uma inclusão mineral hospedada em um grão de cassiterita derivado desse pegmatito. Nele, o teor determinado foi de até $48,3 \%$, em peso, de $\mathrm{HfO}_{2}$ (Pereira et al. 2003b). O zircão hafnífero mostra inclusões de cassiterita, báriomicrolita, plumbomicrolita, tantaeuxenita, brabantita, monazita e thorogumita (Pereira et al. 


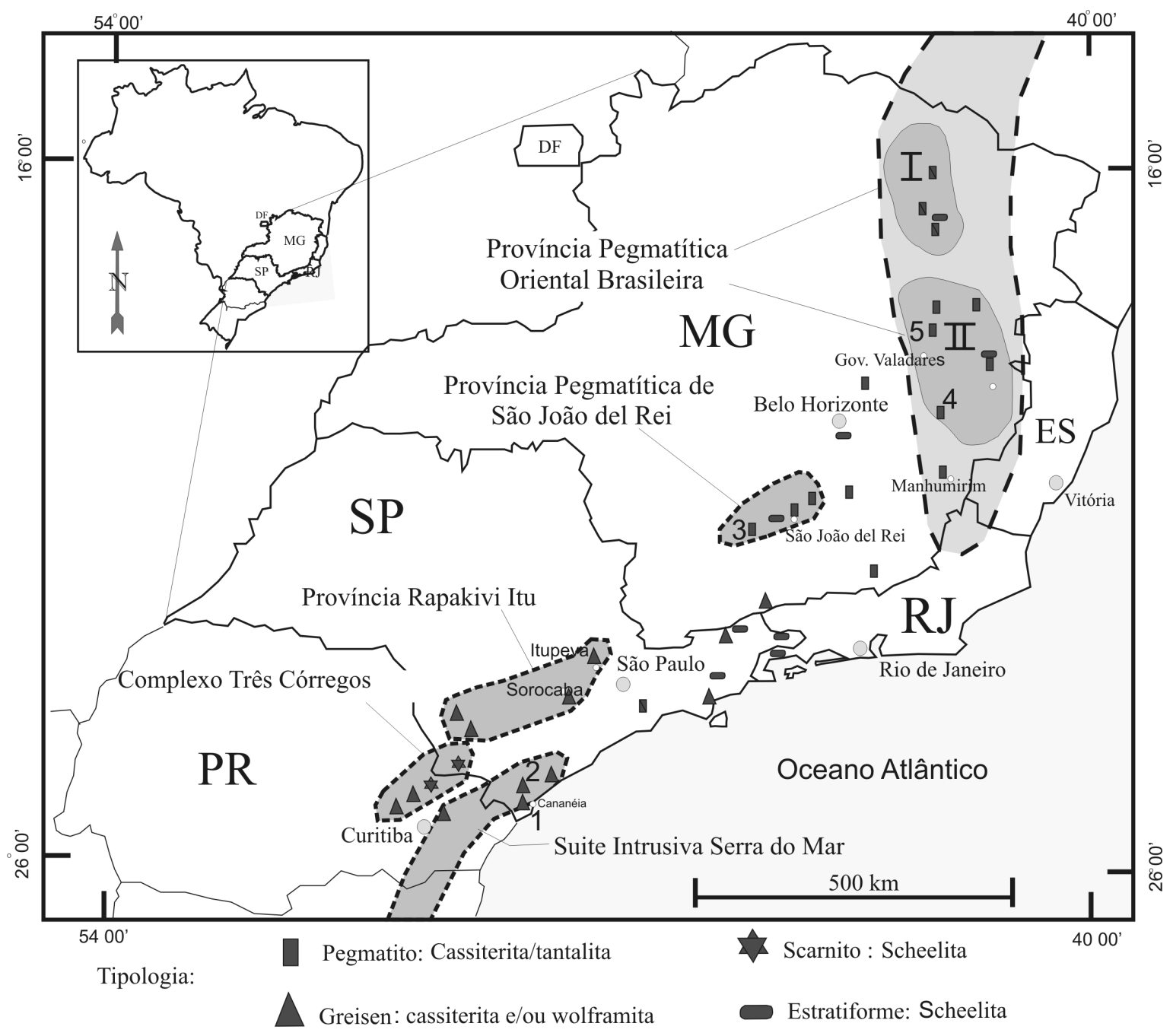

Figura 1 - Mapa de localização das áreas com as ocorrências de zircão hafnifero no sudeste brasileiro: 1 = riebeckita álcali-feldspato granito Mandira; 2 = plúton Desemborque; $3=$ Pegmatito Volta Grande; 4 = Pegmatito Mixiriqueira; 5 = Pegmatito Golconda.

2004b, Saez et al. 2005), enquanto no hafnão zirconífero as inclusões são de cassiterita e microlita. A torita corresponde a principal exsolução encontrada nesses grãos.

\section{PROVÍNCIA PEGMATÍTICA ORIENTAL BRASI- LEIRA}

Distrito Pegmatítico de Governador Valadares Este distrito encontra-se situado na região do Médio Rio Doce, porção leste do Estado de Minas Gerais. Ela engloba as cidades de Governador Valadares, Conselheiro Pena, Mendes Pimentel, Galiléia e Ipatinga, dentre outras. As principais unidades em destaque desta província são do Neoproterozóico e encontram-se intrudidas por diversos tipos de rochas graniticas, de idades entre $600 \mathrm{Ma}$ e $550 \mathrm{Ma}$, dentre os quais sobressaem os tonalitos Governador Valadares, Galiléia e São Vítor e o Granito Palmital (CODEMIG 2003). Estes granitóides são os prováveis responsáveis pelos numerosos corpos pegmatíticos (e.g., Golconda, Córrego Frio, Sapucaia, Lavra do Telírio, etc.) encontrados nessa região. Os pegmatitos foram geralmente posicionados como so- leiras e diques, têm formas geralmente lenticulares, extensões e espessuras variáveis e, encontram-se preferencialmente, encaixados em micaxistos pertencentes às formações Dom Silvério e Tumiritinga (região de Governador Valadares) e São Tomé (na região de Galiléia/Mendes Pimentel). Os pegmatitos da província pegmatítica Oriental Brasileira são importantes produtores de gemas (água-marinha, turmalina, kunzita, etc.) e minerais de fosfato, como a brazilianita (Córrego Frio). Alguns pegmatitos são produtores de caulim, a partir da alteração do feldspato como, por exemplo, o pegmatito Mixiriqueira, situado na região de Ipatinga (Cassedanne et al. 1985).

O PEGMATITO GOLCONDA Este corpo, situado no Município de Governador Valadares, é um dos mais expressivos que compõem a área pegmatítica do Médio Rio Doce. Os pegmatitos desta área intrudem um conjunto de direção N-S, formado por (moscovita, granada e sillimanita) biotita xistos intercalados com quartzitos, da Formação Dom Silvério, do Grupo Rio Doce (CODEMIG 2003). Ortonaisses bandados do Complexo 
Tabela 1 - Análise em microssonda do zircão rico em háfnio derivado dos pegmatitos Volta Grande e Mixiriqueira.

\begin{tabular}{c|c|c|c|c|c|c|c|c|c|c|c}
\hline grão & M1 & M2 & M3 & M4 & M5 & SJ1a & SJ1b & SJ2a & SJ2b & SJ3a & SJ3b \\
\hline $\mathrm{SiO}_{2}$ & 20,5 & 29,2 & 24,8 & 25,9 & 26,2 & 29.4 & 30.4 & 28.7 & 30.3 & 28.9 & 30.5 \\
\hline $\mathrm{ZrO}_{2}$ & 54,0 & 57,9 & 44,9 & 38,8 & 44,1 & 45.3 & 51.2 & 40.4 & 54.1 & 40.5 & 53.6 \\
\hline $\mathrm{HfO}_{2}$ & 8,4 & 8,9 & 7,1 & 23,1 & 21,0 & 24.1 & 17.5 & 29.2 & 14.5 & 31.0 & 15.1 \\
\hline $\mathrm{ThO}_{2}$ & - & - & 0,9 & 4,1 & 0,8 & - & - & 0.1 & 0.1 & - & 0.2 \\
\hline $\mathrm{UO}_{3}$ & 3,2 & 0,6 & 9,5 & - & - & - & - & - & - & - & - \\
\hline $\mathrm{FeO}$ & 0,3 & 0,2 & 0,4 & - & 0,3 & 0.1 & 0,1 & - & - & - & 0,1 \\
\hline $\mathrm{Y} 2 \mathrm{O}$ & 4,1 & 1,3 & 1,9 & 1,7 & 4,6 & 0.1 & - & 0.3 & 0,6 & 0.01 & 0,4 \\
\hline $\mathrm{MnO}$ & 0,3 & 0,2 & - & 0,8 & - & - & - & - & - & - & - \\
\hline $\mathrm{CaO}$ & - & 0,1 & 0,6 & 0,3 & - & - & - & - & 0,1 & - & 0,1 \\
\hline $\mathrm{Total}$ & 90,8 & 98,4 & 90,1 & 94,7 & 97,0 & 99.1 & & 98.9 & & 100.5 & \\
\hline
\end{tabular}

M = Mixiriqueira (Cassedanne et al. 1985); SJ = São João Del Rei: $\mathrm{a}=$ parte clara; $\mathrm{b}=$ parte escura (Pereira et al. 2003).
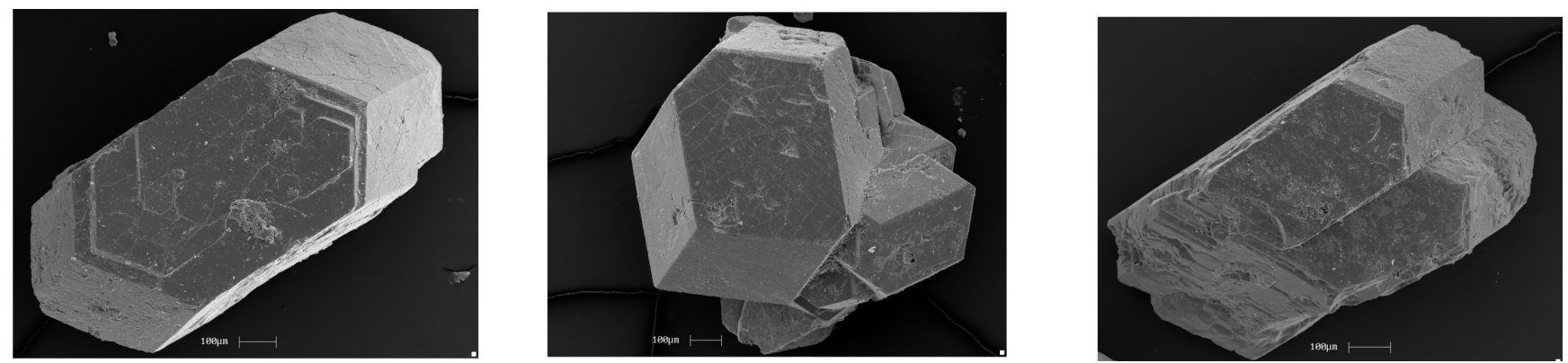

Figura 2 - Imagens MEV/BSD de cristais de zircão da Província Pegmatítica de São João del Rei.

Guanhães, com idade de $2.8 \mathrm{Ga}$, predominam na porção leste da área e a oeste, situam-se os corpos intrusivos do tonalito Governador Valadares, relacionado ao evento Neoproterozóico III (CODEMIG 2003). Nessa área, os pegmatitos comumente apresentam composições mineralógicas simples, sendo formados por quartzo, feldspato, micas, granada e turmalina preta. Mineralogia mais variada, representada por cassiterita, columbita-tantalita, lepidolita, minerais secundários de urânio, fosfatos de $\mathrm{Fe}$ e $\mathrm{Mn}$, turmalina e berilo de várias cores, além do quartzo, feldspato, mica, granada e zircão é observada em alguns corpos (Oliva 1983).

Caracterização do zircão $\mathrm{O}$ zircão ocorre em cristais euédricos, com aproximadamente $2 \mathrm{~mm}$ de comprimento, formas prismática bipiramidada e flabeliforme e cores que vão do rosa ao marrom escuro. Intercrescimentos de zircão com um xenotímio extremamente enriquecido ( 14\%) em elementos terras raras são freqüentemente observados (Fig. 4). Variações nos conteúdos em $\mathrm{HfO}_{2}$ do zircão chegam, nas partes mais claras, a até $15,2 \%$, em peso (Fig. 5). A principal inclusão observada corresponde ao xenotímio sendo a torita, seguida da ura- ninita, as exsoluções observadas.

O PEGMATITO MIXIRIQUEIRA O pegmatito aflora ao norte de Ipatinga e a sudoeste de Governador Valadares, na margem esquerda do rio Doce. Esse corpo encontra-se completamente alterado (caulinizado) e intrudindo micaxistos e gnaisses, do Neoproterozóico e Arqueano (CODEMIG 2003; Cassedanne et al. 1985). Sua composição mineralógica inclui quartzo leitoso, mica, berilo, monazita, espessartita, xenotímio, bismuto nativo, hematita, autunita, samarskita, columbita e zircão hafnífero. O zircão hafnífero apresenta-se em grupos flabeliformes ou maciços e podem ultrapassar os $15 \mathrm{~cm}$ (Cassedanne et al. 1985). São ligeiramente zonados e suas cores variam de rosa alaranjada e bege alaranjado pálido, com as partes mais internas dos cristais mais transparentes e mais acinzentadas.

Caracterização do zircão $\mathrm{O}$ tipo flabeliforme tem teores (em peso) de $\mathrm{HfO}_{2}$ variando entre 7,1\% e 8,9\%, enquanto o tipo maciço tem até $23,1 \%$. Os grãos de zircão (Fig. 6) mostram partes mais claras, mais enriquecidas em háfnio, e mais escuras, menos enrique- 

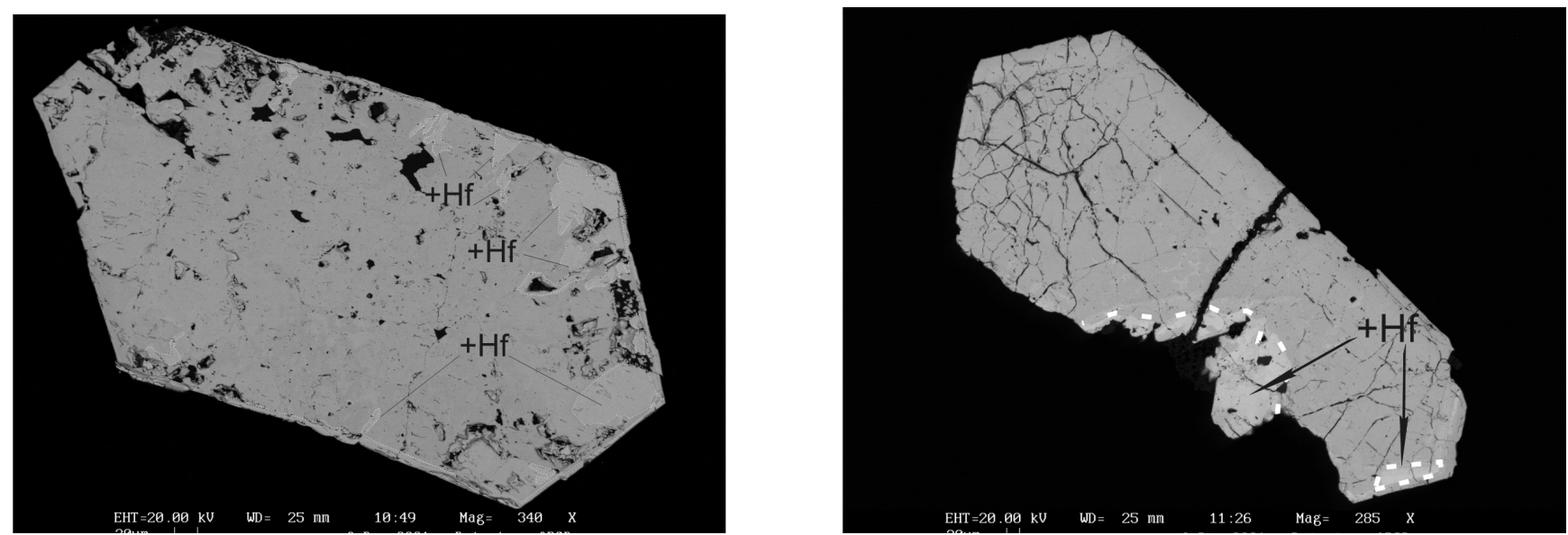

Figura 3 - Imagens MEV/BSD de cristais de zircão mostrando partes mais enriquecidas (mais claras) em háfnio.
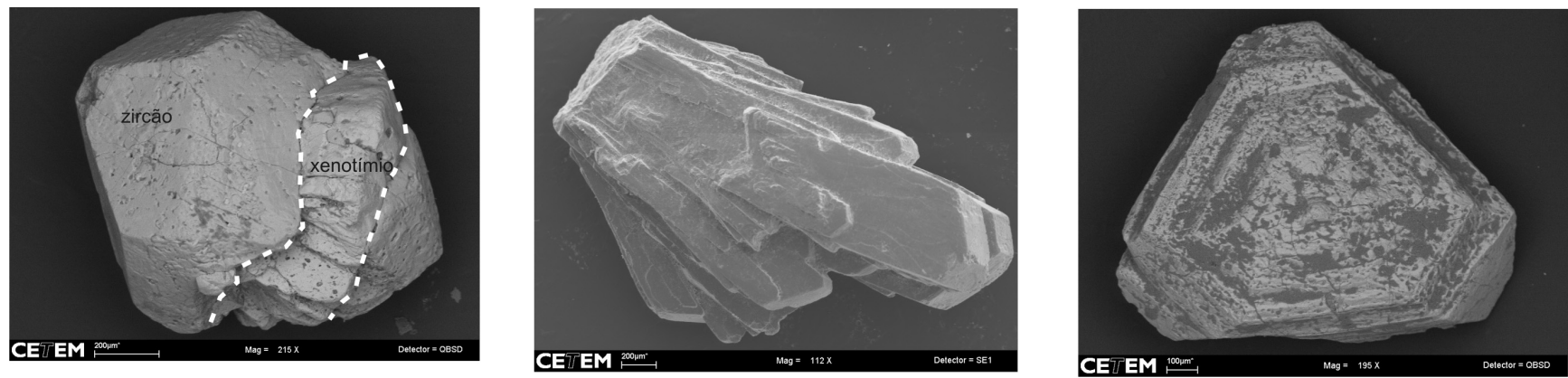

Figura 4 - Imagens MEV/BSD de cristais de zircão do Pegmatito Golconda. O cristal da esquerda apresenta intercrescimento com xenotímio.

cidas nesse elemento. Y representa um elemento secundário na composição do zircão flabeliforme e um elemento principal no tipo maciço (Cassedanne et al. 1985). Estudos complementares em MEV/EDS permitiram identificar algumas inclusões bem características de xenotímio e chernovita.

\section{ZIRCÃO HAFNÍFERO ASSOCIADO ÀS ROCHAS GRANÍTICAS}

Plúton Desemborque $\mathrm{O}$ plúton Desemborque, um granito a metais raros do tipo-A, constitui uma intrusão com forma circular, com área aflorante de $50 \mathrm{~km}^{2}$, situado no sul do Estado de São Paulo. Esse corpo, que pode ser correlacionado ao evento Neoproterozóico III, é formado por biotita sienogranito contendo columbita, zircão hafnífero e cassiterita na associação de minerais acessórios (Pereira et al. 2003b). Processos de alterações, tardi- a pós-magmáticos, tais como metassomatismo sódico, greisenização, epidotização, sulfetização e martitização foram registrados nesse corpo. A priori, pelas mineralizações apresentadas, ele poderia ser enquadrado no modelo dos granitos peralcalinos e anorogênicos mineralizados a metais raros que formam depósitos ou ocorrências de $\mathrm{Nb}, \mathrm{Zr}$ e ETR.

CARACTERIZAÇÃO DO ZIRCÃO O zircão hafníf- ero do plúton Desemborque ocorre em cristais euédricos (Fig. 7) com forma prismática bipiramidada, alguns são geminados, tem tamanhos menores que $1,0 \mathrm{~mm}$, cor rósea a bege, ligeiramente amarronzada. Análises em $\mathrm{MEV} / \mathrm{EDS}$ mostraram teores, em peso, de $\mathrm{HfO}_{2}$ entre $12,6 \%$ e $15,6 \%$. Os maiores valores de háfnio foram obtidos nas zonas mais claras que podem ser observadas nas imagens MEV/BSD (Fig. 8). As inclusões observadas são de magnetita, monazita, xenotímio, bastnäsita, quartzo, mica e anfibólio da série tremolita-actinolita. A torita constitui a principal exsolução encontrada, seguida de uraninita.

Riebeckita Álcali-Granito Mandira O riebeckita álcali-granito Mandira, um dos corpos que constituem o maciço granitóide Mandira (Boin et al. 1982) é relacionado à Suíte Intrusiva Serra do Mar (Kaul et al. 1982). Corresponde a um corpo alcalino, peralcalino, do tipo-A, tem área de exposição de cerca de $50 \mathrm{~km}^{2} \mathrm{e}$ sua idade deve ser próxima a do Granito Serra do Paratiú, que também pertence à mesma suíte e tem idade

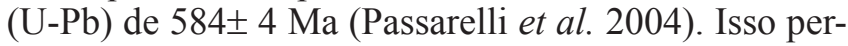
mite o seu enquadramento no evento Neoproterozóico III. O granito é constituído por quartzo, ortoclásio, que se encontra invariavelmente pertitizado e riebeckita, o principal mineral máfico associado, que forma pris- 
Tabela 2 - Análise semiquantitativa em MEV/EDS do zircão hafnifero.

\begin{tabular}{c|c|c|c|c|c|c|c|c|c|c}
\hline Grão & $1 \mathrm{~A}$ & $2 \mathrm{~A}$ & $3 \mathrm{~A}$ & $4 \mathrm{~A}$ & $5 \mathrm{~A}$ & $1 \mathrm{~B}$ & $2 \mathrm{~B}$ & $3 \mathrm{~B}$ & $4 \mathrm{~B}$ & $5 \mathrm{~B}$ \\
\hline $\mathrm{SiO}_{2}$ & 28,3 & 27,8 & 27,8 & 28,0 & 28,2 & 27,5 & 27,5 & 28,7 & 27,4 & 27,2 \\
\hline $\mathrm{ZrO}_{2}$ & 53,0 & 49,3 & 54,2 & 53,1 & 52,5 & 57,5 & 56,6 & 48,4 & 57,1 & 59,1 \\
\hline $\mathrm{HfO}_{2}$ & 12,9 & 15,6 & 12,6 & 13,1 & 14,4 & 12,0 & 9,0 & 11,2 & 12,1 & 11,2 \\
\hline $\mathrm{P}_{2} \mathrm{O}_{5}$ & 5,1 & 4,0 & 4,6 & 5,1 & 4,5 & 0,9 & 1,7 & 4,5 & 1,8 & 0,4 \\
\hline $\mathrm{FeO}$ & - & 1,9 & 0,1 & 0,1 & 0,1 & 0,5 & 0,6 & 0,8 & 0,2 & 0,1 \\
\hline $\mathrm{SnO}_{2}$ & - & - & - & - & - & - & 0,3 & 0,5 & 0,2 & - \\
\hline $\mathrm{UO}_{3}$ & 0,3 & 0,5 & 0,2 & 0,1 & - & 0,2 & 0,7 & 0,7 & 0,2 & 0,4 \\
\hline $\mathrm{ThO}_{2}$ & - & 0,3 & 0,1 & 0,3 & - & 0,1 & 1,2 & 2,4 & 0,1 & - \\
\hline $\mathrm{EuO}_{3}$ & - & 0,1 & - & - & - & 0,3 & - & 0,3 & 0,2 & - \\
\hline $\mathrm{Gd}_{2} \mathrm{O}_{3}$ & 0,1 & - & - & - & - & - & - & 0,3 & - & - \\
\hline $\mathrm{Dy}_{2} \mathrm{O}_{3}$ & - & - & - & - & 0,1 & 0,1 & 0,4 & 0,7 & - & 0,1 \\
\hline $\mathrm{Yb}_{2} \mathrm{O}_{3}$ & 0,2 & 0,2 & 0,1 & - & 0,1 & 0,3 & 1,0 & 0,9 & 0,4 & 0,7 \\
\hline $\mathrm{Er}_{2} \mathrm{O}_{3}$ & - & - & - & - & - & 0,2 & 1,0 & 0,5 & - & 0,4 \\
\hline $\mathrm{Total}^{2}$ & 99,9 & 99,8 & 100,0 & 100,0 & 100,0 & 99,6 & 100,0 & 99,9 & 99,7 & 99,6 \\
\hline
\end{tabular}

Tabela 2 (cont.) - Análise semiquantitativa em MEV/EDS do zircão hafnifero.

\begin{tabular}{c|c|c|c|c|c|c|c|c|c|c}
\hline Grão & $6 \mathrm{~B}$ & $7 \mathrm{~B}$ & $1 \mathrm{C}$ & $2 \mathrm{C}$ & $3 \mathrm{C}$ & $4 \mathrm{C}$ & $1 \mathrm{D}$ & $2 \mathrm{D}$ & $3 \mathrm{D}$ & $6 \mathrm{D}$ \\
\hline $\mathrm{SiO}_{2}$ & 26,9 & 27,5 & 27,5 & 28,0 & 28,1 & 27,8 & 30,0 & 30,0 & 29,5 & 30,3 \\
\hline $\mathrm{ZrO}_{2}$ & 58,9 & 58,0 & 55,6 & 49,4 & 55,3 & 55,2 & 45,0 & 46,4 & 40,0 & 51,4 \\
\hline $\mathrm{HfO}_{2}$ & 11,8 & 11,4 & 14,3 & 15,2 & 13,8 & 15,2 & 24,8 & 23,4 & 30,4 & 17,7 \\
\hline $\mathrm{P}_{2} \mathrm{O}_{5}$ & 1,1 & 0,9 & - & 5,2 & 0,3 & 0,8 & - & - & - & - \\
\hline $\mathrm{FeO}$ & - & - & 0,7 & 0,1 & 0,6 & 0,7 & - & - & - & - \\
\hline $\mathrm{SnO}_{2}$ & - & - & - & - & - & - & - & - & - & - \\
\hline $\mathrm{UO}_{3}$ & - & 0,2 & 1,7 & 1,3 & 1,3 & 0,2 & - & - & - & - \\
\hline $\mathrm{ThO}_{2}$ & 0,1 & 0,9 & - & 0,2 & - & - & - & - & - & 0,3 \\
\hline $\mathrm{EuO}_{3}$ & - & 0,1 & - & - & - & - & - & - & - & - \\
\hline $\mathrm{Gd}_{2} \mathrm{O}_{3}$ & - & 0,4 & 0,1 & 0,2 & 0,2 & 0,2 & - & - & - & - \\
\hline $\mathrm{Dy}_{2} \mathrm{O}_{3}$ & - & - & - & - & - & - & - & - & - & - \\
\hline $\mathrm{Yb}_{2} \mathrm{O}_{3}$ & 0,9 & 0,3 & - & - & 0,1 & 0,2 & - & - & - & - \\
\hline $\mathrm{Er}_{2} \mathrm{O}_{3}$ & 0,4 & 0,6 & 0,1 & 0,3 & 0,1 & 0,2 & - & - & - & - \\
\hline $\mathrm{Total}$ & 100,1 & 100,3 & 100,0 & 99,9 & 99,8 & 100,5 & 99,8 & 99,8 & 99,9 & 99,7 \\
\hline
\end{tabular}

(A) plúton Desemborque (B) Riebeckita Álcali-Granito Mandira;

(C) =Pegmatito Golconda; (D) = Pegmatitos Volta Grande; (-) = não determinado

mas alongados com $1 \mathrm{~cm}$ de comprimento (Boin et al. 1982). O zircão enriquecido em háfnio é um de seus minerais acessórios (Pereira et al. 2005).

CARACTERIZAÇÃO DO ZIRCÃO Os cristais de zircão são euédricos, predominantemente bipiramidais
(Fig. 9) de cor bege a marrom, com até 3,0mm de comprimento. Cristais prismáticos bipiramidados de tamanhos mais reduzidos $(1,0 \mathrm{~mm})$ e tonalidades entre branca leitosa e rosada ocorrem localmente. Alguns cristais apresentam-se zonados. As imagens MEV-BSD mostram que, em alguns grãos de zircão as bordas são mais maciças (e mais enriquecidas em háfnio) em relação às 

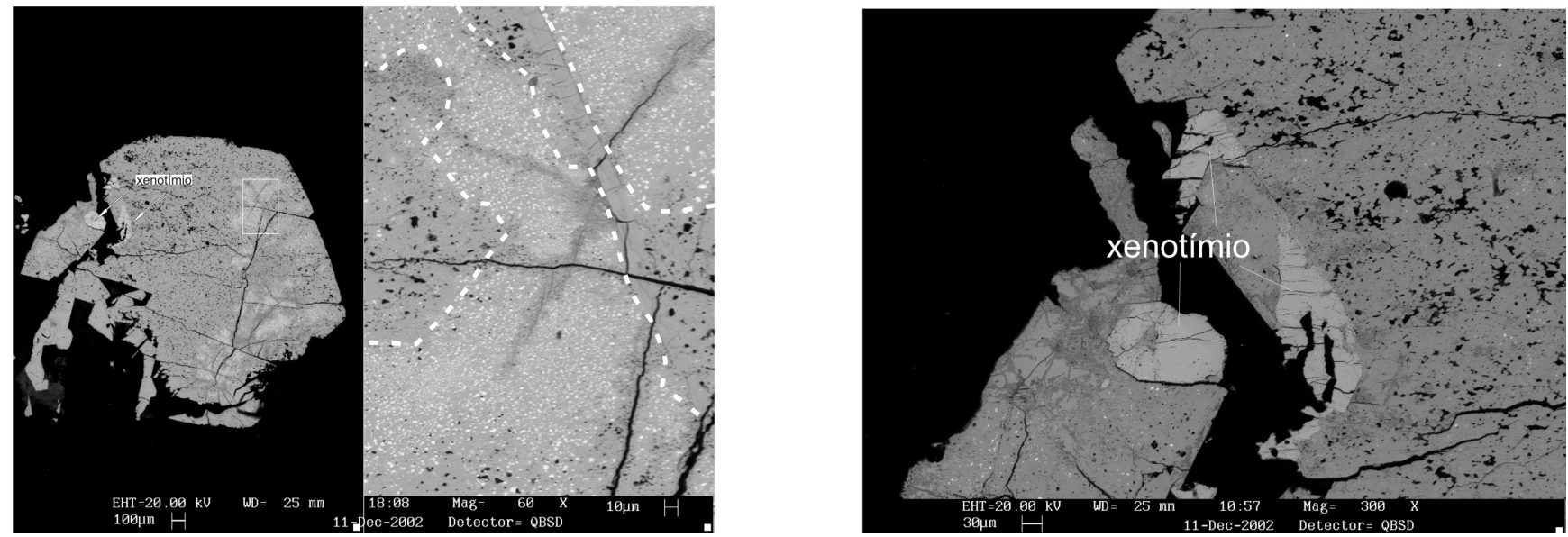

Figura 5 - Imagens MEV/BSD de um fragmento de zircão maciço do Pegmatito Mixiriqueira mostrando zonas mais enriquecidas em háfnio (mais claras), uma inclusão de xenotímio e uma miríade de exsoluções, principalmente, de torita (imagem da direita).
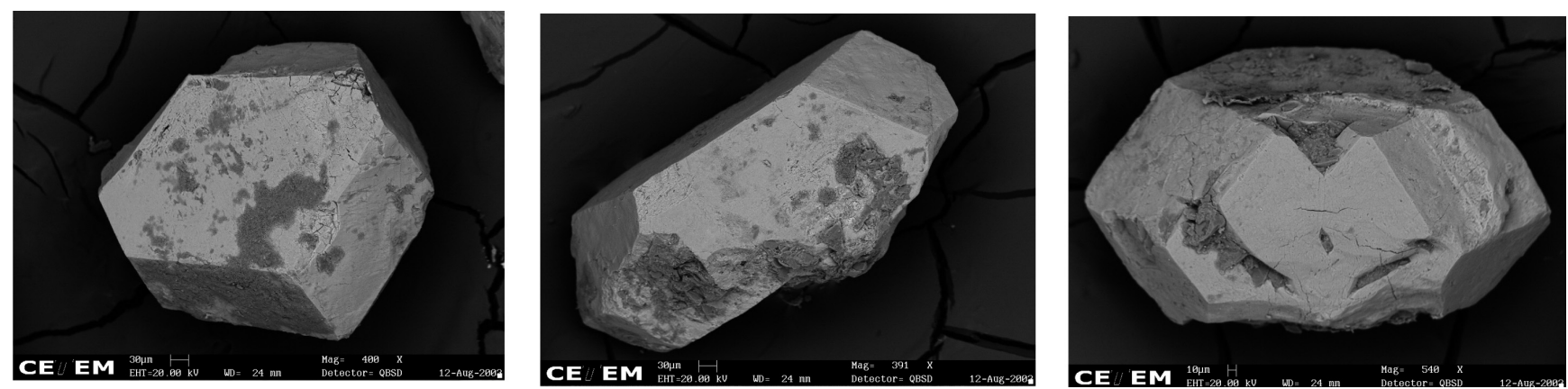

Figura 6 - Imagens MEV/ BSD de cristais de zircão do plúton Desemborque.
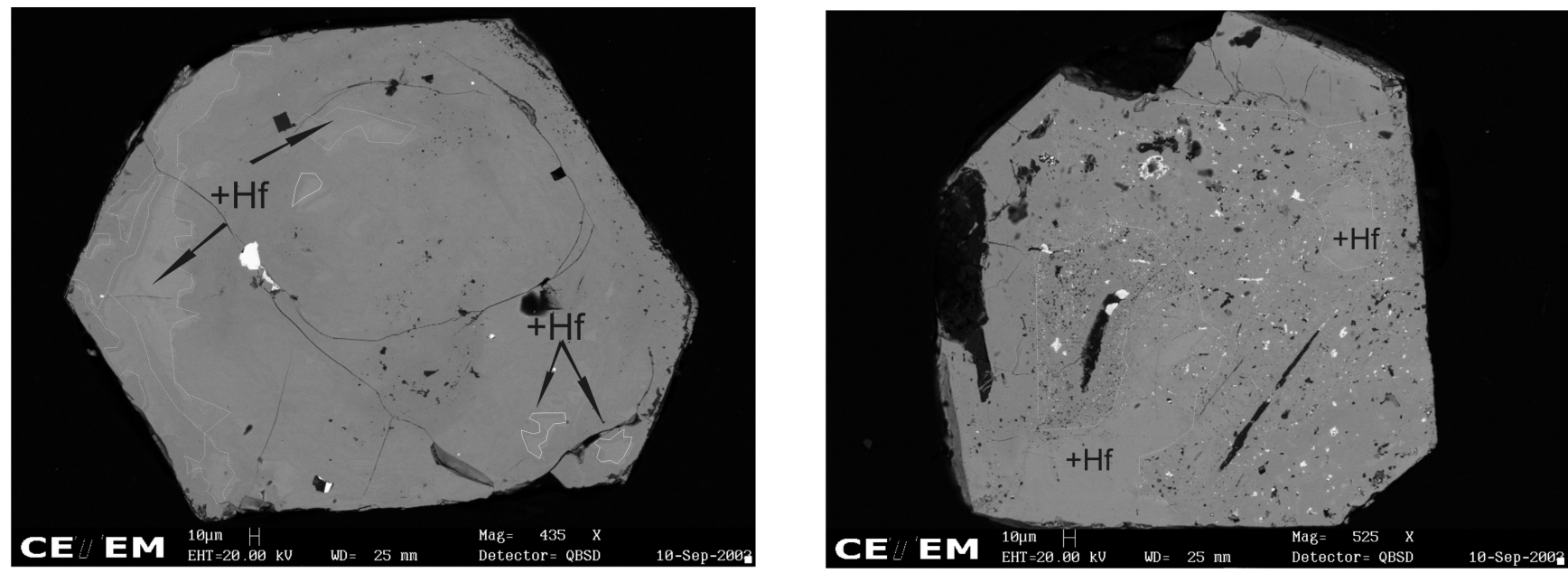

Figura 7 - Imagens MEV/BSD de cristais de zircão do plúton Desemborque mostrando as zonas mais enriquecidas em háfnio (mais claras).

partes mais internas, que se apresentam mais porosas e repletas de inclusões minerais (Fig. 10). Os teores de $\mathrm{HfO}_{2}$ (em peso) entre $9 \%$ e $12 \%$, permitem considerálo dentro da série zircão-hafnão, entre os termos zircão e zircão hafnífero (razões atômicas entre 8,5 e 11,9 mol. $\left.\% \mathrm{HfSiO}_{4}\right)$. Os teores de elementos terras raras podem atingir até 2,7\%, em peso, com destaques para o $\mathrm{Yb}$ e o Er.

A torita é a principal exsolução sendo as inclusões sólidas representadas pelo xenotímio e por um carbonato de terras raras (possivelmente bastnäsita). Também foram registradas inclusões de monazita, óxido de 

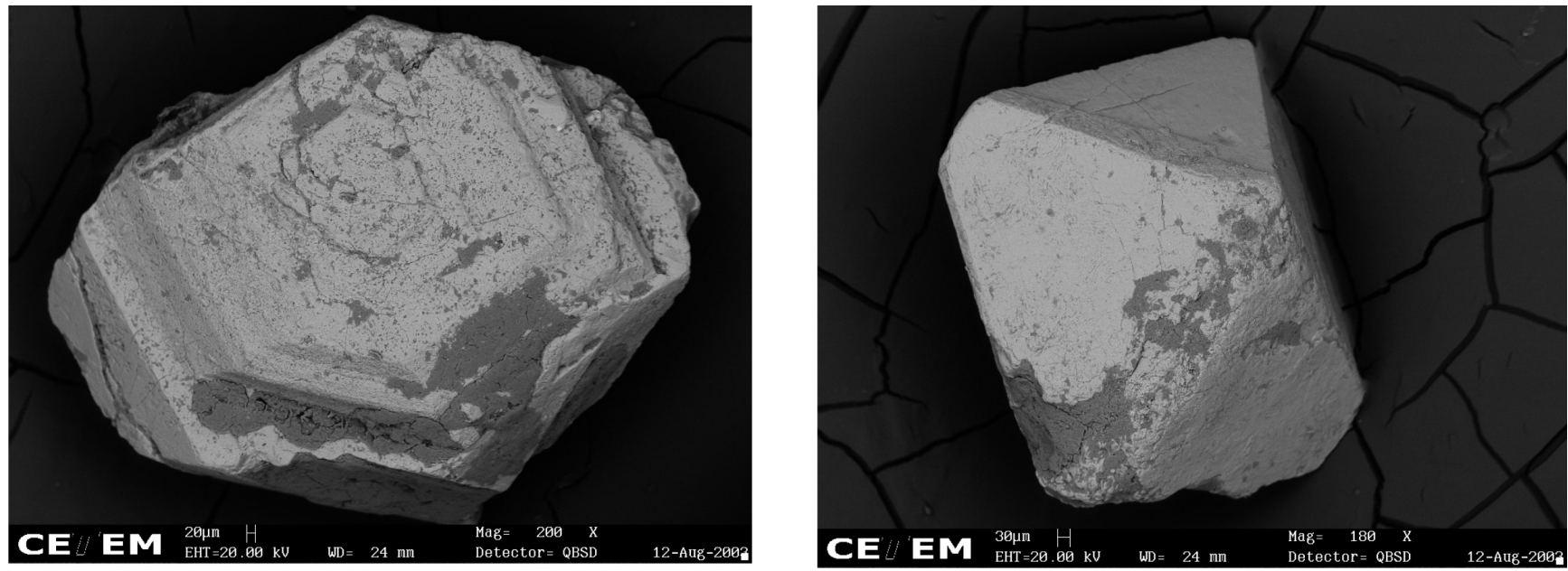

Figura 8 - Imagens MEV/BSD de cristais de zircão do riebeckita álcali-granito Mandira.
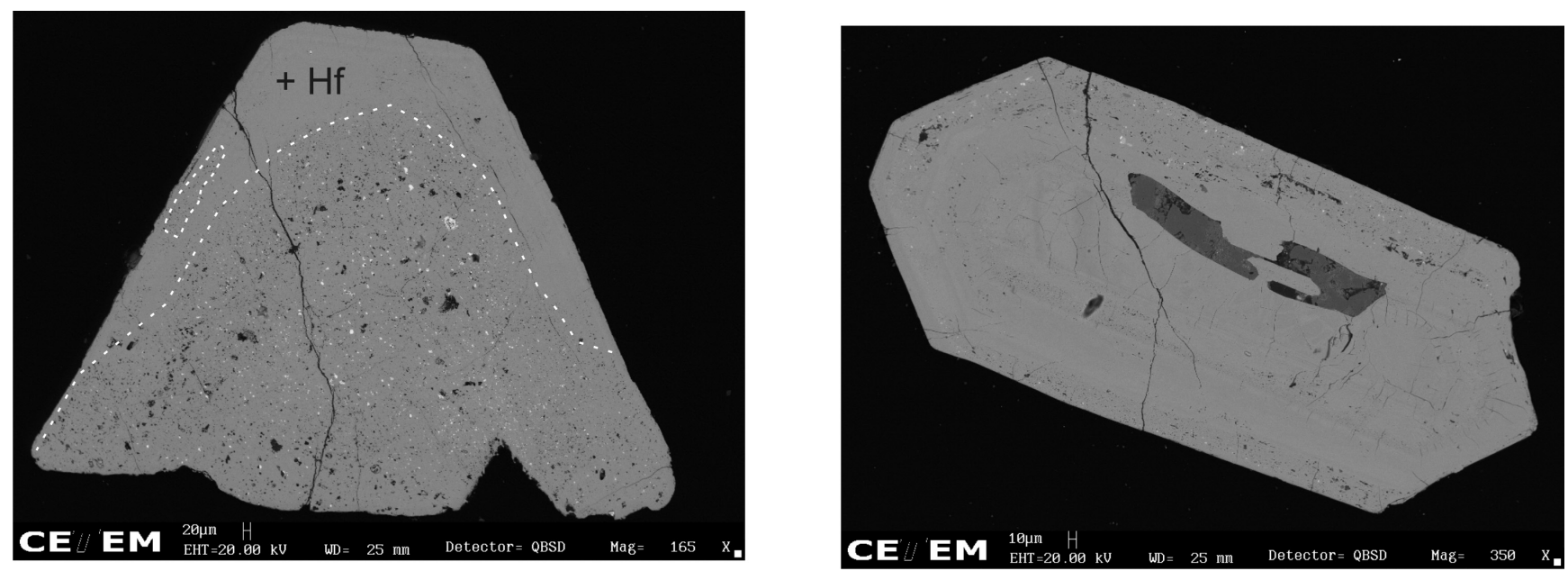

Figura 9 - Imagens MEV/ BSD de cristais de zircão do riebeckita álcali-granito Mandira mostrando as zonas mais enriquecidas em $\mathrm{HfO}_{2}$ (mais claras) e zoneamento do tipo oscilatório (imagem da direita).

ferro (magnetita?), quartzo, feldspato potássico e de um mineral, não identificado, cuja composição corresponde a um fosfato de tório.

CONSIDERAÇÕES FINAIS As ocorrências de zircão hafnífero descritas em território brasileiro são restritas a região sudeste do Brasil associadas a pegmatitos ou a granitos alcalinos inseridos em três grandes domínios metálicos favoráveis para a presença de mineralizações de Sn e metais do grupo dos elementos HFS $(\mathrm{Nb}, \mathrm{Ta}, \mathrm{Be}, \mathrm{Li}$, etc.). Isso está de acordo com o que foi estabelecido através de estudos desenvolvidos por vários autores (Knorring \& Hornung 1961, Correia Neves et al. 1974, Wang et al. 1996, Cerný \& Silvola 1980) que comprovaram a estreita afinidade existente entre o háfnio e o tântalo.

O zoneamento interno dos grãos de zircão varia entre os diversos cristais estudados. As partes mais internas apresentam uma maior abundância de exsoluções/inclusões do que as bordas, geralmente mais homogêneas e às vezes, com zoneamento oscilatório.
Os estudos efetuados demonstram um maior enriquecimento em Hf nas zonas de bordas dos cristais de zircão em detrimento das zonas mais internas. Foram evidenciadas, na estrutura do núcleo de alguns cristais da região de São João Del Rei, texturas do tipo pseudocoloformes semelhantes as descrita para cristais de zircão de origem hidrotermal (Saez et al. 2005). As inclusões contidas no zircão, essencialmente de minerais ricos em elementos incompatíveis como Y, Nb, Ta, ETR, Th e U, refletem o seu crescimento em um meio saturado em fases que incluem esses elementos. A partir dos estudos efetuados em amostras de São João Del Rei, sugere-se uma origem complexa para a formação do zircão com a participação de processos de cristalização fracionada e remobilização de determinados elementos em relação a fluidos hidrotermais de alta temperatura (Saez et al. 2005). Basicamente, os minerais hospedados no zircão rico em háfnio (cassiterita, columbita-tantalita, microlita) são comuns nos pegmatitos e granitos a metais raros.

As ocorrências pegmatíticas brasileiras estão 
relacionadas aos corpos da região de São João Del Rei (Corpo E do Volta Grande, Garimpo do Cascalho Preto e Córrego Pernambuco) e do distrito de Governador Valadares (Mixiriqueira e Golconda). O teor máximo de $\mathrm{HfO}_{2}$, registrado em cristais derivados dos pegmatitos, chegou a $36 \%$ (em peso).

$\mathrm{O}$ zircão hafnífero associado a granitos tem teores (em peso) de háfnio mais baixos, da ordem de $16 \%$ e, até o presente momento, só foi reconhecido no plúton Desemborque e riebeckita álcali-feldspato granito Mandira. Essas últimas descobertas abrem novas perspectivas metalogênicas para os tipos alcalinos relacionados à Suíte Intrusiva Serra do Mar.

As características cristaloquímicas conferem ao zircão uma grande estabilidade na maioria dos ambientes geológicos, particularmente no ambiente exógeno. Sua resistência aos processos de intemperização faz com que a sua presença seja bastante comum nas amostras de concentrados de bateia. Além disso, sua estrutura abriga uma grande abundância de elementos menores e traços, de modo que a sua composição química passa a ser uma fonte significativa de informações no estudo da origem e evolução das rochas derivadas de processos endógenos (Hoskin \& Shaltegger 2003). Dessa maneira, a freqüente relação entre zircão hafnífero e corpos graníticos e pegmatíticos a metais raros faz com que esse mineral se torne, prospectivamente, um interessante rastreador para esse tipo de mineralização.

Agradecimentos RMP agradece à FAPERJ (Processo E:26/171.016) pelo apoio financeiro. Aos revisores da RBG, na pessoa do Prof. Dr. Daniel Atencio, nossos agradecimentos pelas correções e sugestões.

\section{Referências}

Ávila C.A. 2000. Geologia, petrografia e geocronologia de corpos plutônicos Paleoproterozóicos da borda meridional do Cráton São Francisco, região de São João Del Rei, Minas Gerais. Tese de Doutoramento, Instituto de Geociências, Univ. Federal do Rio de Janeiro, 401p.

Boin M.N., Silva J.R.B., Silva R.B., Mello I.S.C. 1982. Mineralizações polimetálicas hidrotermais, associadas aos granitóides alcalinos de Mandira, SP. In: SBG, Cong. Bras. Geol., 22,. Anais, v.3, p.945-955.

Cassedanne J.P., Baptista A., Černý P. 1985. Zircon hafnifère, samarskite et columbite d'une pegmatite du rio Doce, Minas Gerais, Brésil. Canad. Mineral., 23:563-567.

Černý P. \& Silvola J. 1980. Extreme fractionation in rareelement pegmatites selected examples of data and mechanisms. Canad. Mineral., 18:313-321.

CODEMIG 2003. Mapa geológico do Estado de Minas Gerais, Escala 1:100.0000. CD-ROM.

Correia Neves J.M., Lopes Nunes J.E., Sahama G. 1974. High hafnium of the zircon-hafnon series from the granite pegmatites of Zambézia, Mozambique. Contrib. Mineral. Petrol., 48(1):73-80.

Hoskin P.W.O. \& Schaltegger U. 2003. In: J.M. Hanchar \& P.W.O. Hoskin (eds.). Zircão, Mineralogical Society of America Revue.Mineralogy and Geochemistry, vol. 53, p.27-62.

Kaul P.F.T., Issler R.S., Fernandes E., Bonow C.W., Coutinho J.B.L. 1982. Suíte Intrusiva Serra do Mar. Min. Metal., 484:32-37.

Knorring O. \& Hornung G. 1961. Hafnium zircons. Nature, 190(17):1098-1099.

Levinson A.A. \& Borup R.A. 1960. High hafnium zircon from Norway. Am. Mineral., 45(5-6):562-565.

Oliva P.R. 1983. Prospecção com bateia na região pegmatítica da Golconda: município de Governador Valadares, $M G$. Dissertação de Mestrado, Instituto de Geociências, Universidade Federal do Rio de Janeiro, 150p.

Passarelli C.R., Basei M.A. S., Campos Neto M.C., Siga Júnior O., Prazeres Filho H.J. 2004. Geocronologia e Geologia Isotópica dos Terrenos Pré-Cambrianos da Porção sul-oriental do Estado de São Paulo. Revista do Instituto de Geociências, Série Científica, 4(1):55-74.

Pereira R.M., Ávila C.A., Neumann R., Atencio D., Netto A.M. 2003a. Borda de zircão hafnífero em hafnão zirconífero do pegmatito da área da mina do Volta Grande, Província Pegmatítica de São João Del Rei, Minas Gerais. Bol. Museu Nacional, Série Geologia, 69:1-14.

Pereira R.M., Ávila C.A., Neumann R. 2003b. Zircão hafnífero e columbita-tantalita associados ao Granito Guaraú, região de Jacupiranga, Vale do Ribeira, SP. In: SBG, Simp. Geol. Sudeste, 8, Boletim de Resumos, p.135.

Pereira R.M., Ávila C.A., Neumann R., Silva R.B. 2004a. Zircão com alto conteúdo de háfnio da região de $\mathrm{Ca}$ nanéia, São Paulo. In: SBG, Cong. Bras. Geol., 42, Boletim de Resumos, CDrom.

Pereira R.M., Netto A.M., Ávila C.A., Barrueto H.R., Neumann R., Atencio D. 2004b. Zirconiferous hafnon and hafniferous zircon from São João Del Rei, Minas Gerais, Brazil. In: ICAM, International Congress on Applied Mineralogy, 8, Águas de Lindóia, Extend Abstract, v.2, p. 919-921.

Pereira R.M., Bastos R.S., Rezende M.F., Ávila C.A., Neumann R. 2005. Potencial para placeres mineralizados em zircão hafnífero na região de Cananéia, Estado de São Paulo. Rev.Bras. Geoc. 35(4):585-590.

Sáez R., Pereira R.M., Carrasco R., Nieto J.M. 2005.Origen de circones detríticos ricos em Hf de São João Del Rei, Minas Gerais (Brasil). Geogaceta, 37:63-66.

Wang R.C., Fontan F., Xu, S.J., Chen X.M., Monchoux P. 1996. Hafnian zircon from the apical part of the Suzhou granite, China. Canad. Mineral., 34:1001-1010.

Wang R.C., Zhao G.T., Lu J.J., Chen X.M., Xu S.J., Wang D.Z. 2000. Chemistry of Hf-rich zircons from the Laoshan I- and A-type granites, eastern China. Mineral. Mag., 64(5):867-877.

Manuscrito AE-051/2006 Submetido em 30 de outubro de 2006 Aceito em 17 de abril de 2007 